\title{
Personal and environmental factors affecting Hong Kong high-ability students' school satisfaction
}

\begin{tabular}{|r|l|}
\hline Journal: & Journal of Psychologists and Counsellors in Schools \\
\hline Manuscript ID & JGC-OA-2016-0023.R5 \\
\hline Manuscript Type: & Original Article \\
\hline Keywords: & $\begin{array}{l}\text { Chinese; , School satisfaction, Socio-emotional development, High-ability } \\
\text { students }\end{array}$ \\
\hline
\end{tabular}




\section{Introduction}

School satisfaction can be defined as a student's subjective appraisal of the quality of his or her school life (Baker \& Maupin, 2009). Because children spend most of their time at school, their level of school satisfaction undoubtedly affects their personal well-being. School satisfaction is important because it affects children's psychological well-being, school engagement, absentee rates and dropout rates (Ainley, 1991; Reyes and Jason, 1993). Students who have strong school satisfaction tend to exhibit higher grade-point averages (Lewis et al., 2009), behave better in school (DeSantis King et al., 2006; Suldo et al., 2008) and have greater intrinsic motivation to complete their schoolwork (Cock \& Halvari, 1999). This can be interpreted as indicating that all schools have a responsibility to foster students' satisfaction with their school lives and to provide support that will help develop and maintain such satisfaction. The recent rise of the Positive Psychology movement has brought school satisfaction to the attention of both researchers and practitioners in schools (see Huebner \& Diener, 2008). However, many of them have focused on the consequences of students' dissatisfaction (e.g., disengagement, dropping out). Few studies have targeted the environmental factors that contribute to individual differences in school satisfaction (Huebner et al., 2009). Studies have found a range of factors that affect school satisfaction. Personal factors include demographic variables such as gender and grade level (Karatzias et al., 2001).

Okun et al. (1990) found that girls showed more school satisfaction than boys, while other 
Running Head: Personal and environmental factors affecting Hong Kong high-ability students' school satisfaction

researchers showed that boys may be less satisfied with school than girls because boys are more often both the victims and the perpetrators of peer victimisation (Verkuyten et al., 2002). Huebner and his colleagues (2001) found no variation in school satisfaction by gender. In a Chinese setting, Hui and Sun (2010) found no statistically significant sex difference in school satisfaction in Chinese primary school children. Other studies have tried to determine whether school satisfaction significantly correlates with students' age and grade. Okun et al. (1990) found that as students grew older, their school satisfaction declined. Hui and Sun (2010) revealed that school satisfaction in primary students declined with age. They proposed that this decline may be a result of the stress caused by transferring to secondary school, higher academic demands and diminished attention from teachers. Research has indicated that personality factors could also predict school satisfaction (Karatzias et al., 2002). Self-esteem and affectivity were both found to be related to students' satisfaction with their school lives. Verkuyten et al. (2002) showed that perceived scholastic competence mediates the relationship between educational performance and school satisfaction. Environmental factors consisted of perceived social support (DeSantis-King et al., 2006). For example, a study by Beckman et al. (2012) showed that children's enjoyment of schooling declined when they faced poor social relations, such as bullying. Meanwhile, negative social relations also pose a threat to children's mental health and their ability to learn (Gustafsson et al., 2010). Research is scant when it comes to the understanding of the school satisfaction of specific 
Running Head: Personal and environmental factors affecting Hong Kong high-ability students' school satisfaction

subpopulations of students. It is clear that the topic of school satisfaction is pertinent to high-ability students. Although there are few studies related to the school satisfaction of high-ability students, we can refer to research related to the life satisfaction and social adjustment of high-ability students. Peterson (2009) challenged the myth that high-ability students do not have unique social and emotional needs. He pointed out that often the social and emotional needs of high-ability students are not recognised in schools. More recent work is found in a study by Fouladchang et al. (2010), showing that high-ability students had lower scores in life satisfaction than non-high-ability students. Because high-ability students are often characterised by their sensitivity, intensity and psychomotor, intellectual, sensual, emotional and imaginational overexciteabilities, Peterson (2009) mentioned that these characteristics could create social difficulties, such as having no intellectual or interest peers at school. Some intellectually high-ability students appear to perceive a conflict between the pursuit of academic success and the maintenance of friendships with their average-ability peers. Gross (1994) called this a 'forced choice dilemma', meaning that high-ability students may deliberately give up their own views to conform to the peer group. Jung et al. (2012) expanded Gross's theory of the 'forced choice dilemma' $(1989,1998)$ by positing that different cultural orientations may place different emphases on the importance of academic achievement and investigating how culture affects high-ability students' choice between academic achievement and peer acceptance. They concluded that cultural orientations that 
Running Head: Personal and environmental factors affecting Hong Kong high-ability students' school satisfaction

emphasise hierarchy among individuals may create a strong motivation for academic success.

Interviewing high-ability students about their perceptions of their peers and understanding how they decide between academic success or acceptance can provide further understanding of how cultural factors influence high-ability students' school satisfaction and provide additional support for the findings of Jung et al. (2012).

While school satisfaction has been widely studied in Western populations, the cultural aspects of the Chinese school contexts and the influence of culture on high-ability students' perceptions of their school lives may be different from their Western counterparts. In Hong Kong, parents, teachers and schools have long considered high academic achievement to be the most important goal of the school years (Hui, 2000). Chinese students are strongly influenced by the traditional Confucian belief that hard work is the only path to success. They are led from an early age to understand that they need to spend abundant time working very hard to achieve good results. The Three Character Classic, a classic Chinese text for teaching Confucianism to children, contains the saying '勤有功, 戲無益’ (qínyŏugōngxìwúyì), which means that diligence will yield merits, but playing will bring no advantage. This shows the hidden belief that one needs to sacrifice play or rest for success. This is part of the reason Hong Kong ranks very highly in international surveys of achievement such as the Programme for International Student Assessment (PISA, 2009), Progress in International Reading Literacy Study (PIRLS) (Tse, 2012) and Trends in International Mathematics and Science 
Running Head: Personal and environmental factors affecting Hong Kong high-ability students' school satisfaction

Study (TIMSS) (Leung, 2012). While these high academic standards are indeed important, it is increasingly believed that the impressive results come at a price, because students in Hong Kong are often reported to have adjustment problems stemming from unrealistically high parental expectations and from school pressures. These pressures can cause students to engage too intensely in their schoolwork, resulting in an unreasonable striving for perfection (Chan, 2003; Fong \& Yuen, 2014). This kind of negative perfectionism, which is characterised by a standards-performance discrepancy, causes lower life satisfaction and underachievement on the part of high-ability students (Chan, 2012). According to Yuen and Fong (2013), the influence of the cultural context and the social environment on high-ability students' social-emotional development needs to be considered in the fostering of excellence. Given the cultural background of an emphasis on academic achievement, high parental expectations and pressure to conform to the peer group, the present study was designed to investigate how high-ability students view their school lives and what contributes to their school satisfaction.

\section{Purpose of the study}

School satisfaction is, of course, important for all students, but it is of particular significance for high-ability students who need to feel very positive about their schools to maintain their motivation and reach their full potential. We are particularly interested in the 
Running Head: Personal and environmental factors affecting Hong Kong high-ability students' school satisfaction

personal and environmental factors described by a group of high-ability students who are also highly satisfied with their school lives. Given high parental and teacher expectations and the strong sense of conformity in Chinese culture, how do the high-ability students overcome the 'forced choice dilemma' (Gross, 1994) and maintain high school satisfaction? Individual interviews were used to approach this question. It was believed that this information could be of practical value to personnel who aim to improve school environments that address the social and emotional needs of high-ability students.

\section{Research Question}

In this study, the following question provided the focus for obtaining information from participants:

Q: What do these high-ability students believe to be the factors that contribute to their school satisfaction?

\section{Method}

Study Background: In 2012-2013, a sample comprising 1671 students from primary and secondary schools in Hong Kong participated in a cross-sectional survey to investigate school satisfaction and social support among school children. The age of the participants varied from 9 to $14(M=12.66, S D=2.07)$. This sample covered the full range of cognitive ability in 
Running Head: Personal and environmental factors affecting Hong Kong high-ability students' school satisfaction

mainstream schools. The information reported here focuses on a much smaller sub-sample of

high-ability students to explore their views on issues related to school satisfaction.

Design: Qualitative analysis (Heieh and Shannon, 2005) was used with data gathered in September 2013 from three primary schools (Primary 4 to 6) and three secondary schools (Secondary 1 to 3 ). The schools were located in different socioeconomic districts in Hong Kong and had participated in the larger cross-sectional survey.

Participants: The sample of 21 students used in this study was obtained from an initial population of 1671 . They were screened with eight questions from the Multidimensional Students' Life Satisfaction Scale (Huebner, 2001) and selected if they recorded high levels of school satisfaction (a score of 24 or above at the +25 th percentile). These students also had high scores (above 81 out of 108 total points) on the Child and Adolescent Social Support Scale (CASSS; Malecki et al., 2000), a 60-item instrument that measures the perceived social support of children and adolescents in Grades 3-12. The scale covers support from parents, teachers, classmates, close friends and school. Instead of looking at grades, the teachers chose the students based on their attitudes towards learning and their overall school performance. The students selected were regarded by their teachers as highly involved in both schoolwork and extra-curricular activities.

Using these criteria, 11 students were chosen from primary schools and 10 from secondary schools. All of the schools with participating students were government-subsidised 
Running Head: Personal and environmental factors affecting Hong Kong high-ability students' school satisfaction

schools. Two of the schools were Catholic schools, while others were run by different educational bodies.

$<$ Insert Table 1 about here $>$

Procedure: Ethics approval for the study was obtained from the Education Research Committee of the University of Hong Kong. The school teachers were informed of the purpose of the study and their role in helping to identify suitable subjects. Participation by students was voluntary. Student and parent consent was obtained before the individual interviews. To protect the privacy of the participants, the data were stored electronically with encryption. In the following descriptions of the data, pseudonyms are used.

\section{Data Collection and Analyses}

The interviews were scheduled by teachers and carried out in a quiet room after school hours. The principal researcher, who is the first author, interviewed the informants individually for about 30 minutes each. All of the interviews were conducted in Cantonese. Data were collected based on a semi-structured interview guide designed for that purpose (see Appendix) - with some common questions for all, some open-ended questions and some probing for more information. With the consent of the participants, the interviews were audio-recorded and supplemented with handwritten notes. The tape recordings and notes were transcribed and typed in Chinese directly after each interview. 
Running Head: Personal and environmental factors affecting Hong Kong high-ability students' school satisfaction

\section{Coding Categories}

For the 21 cases, the data were analysed following the procedure for data display, data interpretation and drawing of conclusions (Miles \& Huberman, 1994). Thematic analysis was used to identify and analyse patterns of meaning in the data we collected (Braun \& Clarke, 2006). Based on the transcripts, commonly occurring themes in the interview data were extracted and categorised. The researcher and an experienced teacher read the transcripts several times and agreed upon the categories that emerged. A coding system was then devised to identify these themes and any others that were found during more detailed analysis. In addition, an experienced social worker was invited to act as an independent reviewer using the same codes. An inter-rater reliability of 0.86 was obtained for this procedure. 
Running Head: Personal and environmental factors affecting Hong Kong high-ability students' school satisfaction

\section{Results}

All 21 students interviewed reported positive attitudes and overall satisfaction with their schools. They were able to give examples of personal experiences, situations and resources that had helped to create their school satisfaction.

The initial hypothesis was that achieving high academic success would be the main influence on school satisfaction in this group, so it was surprising to find that some of their satisfaction was not related in any way to academic success. The students mentioned opportunities their schools gave them to engage in non-academic activities that enabled them to develop other interests and talents.

The specific themes that were identified from the data are described in more detail below, with several verbatim comments (translated into English) used as illustrations of students' responses.

In response to the research question (What did the students believe to be the factors that contributed to their school satisfaction?), several themes were identified and reported here under 'personal influences' and 'environmental influences'.

Personal Influences: Two themes emerged under 'personal influences': 1) goal-directed thoughts and motivation and 2) self-discipline and self-regulation.

Goal-directed thoughts and motivation 
Running Head: Personal and environmental factors affecting Hong Kong high-ability students' school satisfaction

Most of these Chinese high-ability students $(N=18)$ stated that their main reason for going to school and working hard was to perfect themselves academically, socially and morally. They believed school was a stepping stone to economic success in the future. If they felt that the school was helping them in this respect, they had stronger school satisfaction. This supported the original hypothesis that students' school satisfaction mainly came from schooling that prepared them to achieve their personal goals.

Sze-pui, a Primary 4 girl, reported that her purpose in going to school was the following:

I want to go to school because that will prepare me to find a better job. I want to earn an independent living in the future.

Similarly, Ka-man, a Primary 6 girl, revealed that she enjoyed her school life because she viewed school as a path to the future. She had set herself the goal of enrolling in a good secondary school:

I wish to be a lawyer in the future [...] I want to speak out against injustice. I believe that if I attain good results in school, I'll achieve my goals.

Sau-man, a Secondary 3 girl, stated:

I was born in a working-class family. I don't want to be looked down upon by others; that's why I want to be a doctor in the future. I want to have high social status in the future. I know my parents expect me to do that in the same way too.

Pak-hei was a boy in Secondary 1. He remarked that doing well in school would help him 
Running Head: Personal and environmental factors affecting Hong Kong high-ability students' school satisfaction

enrol in a university and achieve his dream:

My dream is to travel around the world. I am working hard in school now

because I wish to study in a university. Getting into a university will help me get

a well-paid job in the future. After I save enough money, I will start my travel

plan. To achieve this, I will prepare well for the public examinations.

All of the informants were able to identify the purpose and value of what they were doing and set up goals they wanted to achieve. For example, Sze-pui's goal was to find a good job, Ka-man wished to become a lawyer, Sau-man wanted to become a doctor and Pak-hei wished to travel around the world. All of these goals reflected students' belief in school and their trust that school could provide ways for them to meet their personal goals. This kind of goal-setting helped keep the adolescents motivated and engaged in their school lives.

In summary, these high-ability students not only set goals for themselves but also had the motivation, hope and strategies to achieve these aims. Their hopes for the future were strong and positive, and their satisfaction with school was influenced by factors that helped them along this path. They perceived school as the means of realizing their dreams.

\section{Self-discipline and self-regulation}

During the interviews, some of the interviewees $(N=12)$ described situations in which they used self-discipline or self-regulation when faced with a problem. In Chinese culture, 
Running Head: Personal and environmental factors affecting Hong Kong high-ability students' school satisfaction

people believe that working hard is far more important than innate intelligence for success.

For example, Pak-hei stated:

I would describe myself as successful in school, though I am not good at everything. I have always tried my best to tackle any difficulties by thinking ahead. If I fail, I will try again and again. I won't easily give up until I can find a solution.

Some high-ability students $(N=11)$ could describe proactive ways to help themselves deal with stress and problems. For instance, Yuen-tsu, another Secondary 1 boy, stated his firm commitment to achieving his goals:

If I want to get good results on the exams, I realise that I need to put in extra time to review the homework during the holidays. I will give up playing video games and tell myself to concentrate and not be easily distracted.

Man-hoo, a Secondary 3 boy, described his love of learning in school:

I love going to school because I can learn new things. For instance, when I have the chance to do challenging mathematics, I feel so excited. When I can solve the challenging questions, I feel really happy that I can overcome the problem and advance my knowledge in maths.

All of these examples showed that the high-ability students possessed personality traits such as self-discipline and a positive attitude in the face of challenges. They showed 
Running Head: Personal and environmental factors affecting Hong Kong high-ability students' school satisfaction

their commitment to learning by pursuing success and belonging in school.

Environmental Influences: Four themes emerged as environmental influences on school satisfaction: 'positive teacher-student relationships', 'classmates' emotional and instrumental support', 'parental involvement in students' learning' and 'talent development opportunities'.

Positive teacher-student relationships

All of these high-ability students $(N=21)$ reported good relationships with teachers. The students described the support teachers gave them in their learning and in their personal well-being. Ka-man described teachers as a resource from whom she sought help when facing problems:

When I have difficulties in my homework, I turn to my teachers. I think my teachers are knowledgeable and capable in giving us advice.

Sau-man commented:

I was quite unmotivated in my studies before I was admitted to the present class.

I started to pick up my interest in studying when I met my present class teacher.

She understands me so well. I am the kind of person who doesn't like to lose in games. She said that if I don't want to lose, I need to prove it to her. Because of 
Running Head: Personal and environmental factors affecting Hong Kong high-ability students' school satisfaction

that, I study hard just to prove my ability.

According to the students' narratives, they not only seek help from teachers in academic matters but also treasure teachers' emotional support. For example, Sau-man reported:

My teachers treated me as if I was their friend. When I was unhappy, they were so ready to listen to me and even hug me to give me strength. Once, something bad happened to my family; I couldn’t help crying. At that time, my teachers just listened and gave me advice.

In addition, many participants $(N=18)$ pointed positively to teachers' sensitivity to the individual needs of students and their offers of responsive help. For example, Yin-mei, a Form 1 girl, reported:

Once I met my teacher in the corridor. He told me that I had made quite a lot of mistakes in my mathematics assignment that I recently handed in. He immediately took out the textbook and reviewed the chapter with me.

Siew-hooi, a Primary 4 girl, commented:

When I was in Primary 1, I had difficulty handing in my homework on time. At that time, my teacher helped me set up a reward plan so that whenever I handed in the homework, she would give me a prize. Finally, my situation improved, and I got the present from the teacher in the end.

Tsz-yan was a Primary 6 girl. She described how her teacher spotted her talent and helped her 
Running Head: Personal and environmental factors affecting Hong Kong high-ability students' school satisfaction

overcome her weakness:

My Chinese teacher knows that I am good at Mandarin. She always encourages me

to join in different competitions to build up my confidence to stand on the stage and

speak up in front of the audience.

From a few of the interviewees' comments, it became clear that they thought some of the teachers put pressure on them to work hard and achieve. These students even regarded some forms of punishment as teachers' way of giving them positive attention and helping them learn better. They accepted that it was part of a teacher's role to motivate them and support them in academic and social life.

Classmates' emotional and instrumental support

These high-ability students valued good companions who were motivated to achieve. Many participants $(N=16)$ reported having positive feelings towards school when they felt their learning was being supported by their peers. For example, Pak-hei reported:

I think classmates have the greatest impact on me for my schooling. Besides my

parents, I spend most of my time with my classmates. We learn and play together.

If my classmates behaved badly, I am sure that would influence me as well.

Mei-ling, a Secondary 2 girl, stated:

My interest lies in painting. I love my school because I can find many classmates 
Running Head: Personal and environmental factors affecting Hong Kong high-ability students' school satisfaction

who are also good at painting. Their paintings inspire me and help me in my

creative work.

Sau-man commented:

My peers have a great influence on me. My weakness is that I am too shy to stand in front of a crowd. I also have stage fright. However, my friends always encourage me to join in solo verse speaking competitions with them to build up my confidence.

Similarly, Shui-fong, a Primary 5 girl, commented:

I like to stay with my peers. When I do not know how to complete an assignment, they are willing to spend time to solve the problem with me. I believe that two heads are better than one.

Yuk-yee highlighted the emotional support of her peers:

Once I had a quarrel with my mother. I did not know what to do. I was feeling so unhappy at that time. I talked to my friend. She listened to me and comforted me. I felt better after my friend listened to me.

The students' comments and narratives made it evident that they were not always in harmony with their peers and sometimes experienced social difficulties. However, most of the students $(N=14)$ revealed their ability to use social coping strategies to resolve peer conflict. For example, Yin-mei stated: 
Running Head: Personal and environmental factors affecting Hong Kong high-ability students' school satisfaction

In my group, I had a friend, but now she doesn't like me at all. I don't know why I

became her enemy after I won the class competition. She persuaded my other

friends to ostracise me, and she spread rumours about me. She even wrote bad things about me in the Whatsapp group. I couldn't bear it any longer. I was so unhappy about it. I turned to my father and other friends for their support. After talking to them, I felt better. I won't put that as a big problem now as I now realise that it is irrational to try to make everyone like you. I feel more mature and more competent in handling this kind of conflict in the future.

These high-ability students mentioned efforts to cope with conflicts due to their differences from their peers. Sze-pui commented:

There are quarrels in my group sometimes ... however, we soon forgive each other.

There are no reasons not to play with each other when there are just minor problems in our relationships.

In summary, the high-ability students who described having positive support from their classmates tended to be more satisfied with their school lives. They enjoyed schooling because they could find peers who shared similar interests. Throughout the interviews, it was clear that these students were not without social problems. These problems could in turn have affected their attitudes towards school. However, with the emotional support and social coping strategies provided by their parents or teachers, 
Running Head: Personal and environmental factors affecting Hong Kong high-ability students' school satisfaction

these students reported improvements in their social adjustment and school lives.

\section{Parental involvement in students' learning}

Some informants $(N=5)$ made comments that indicated that their parents were highly involved in directly supporting their learning by giving time, resources and emotional support in both academic and non-academic areas. For instance, Yin-mei reported:

I have a close relationship with my family. When I am unhappy, I'll talk to my family, especially to my father. I describe my father as my 'counsellor'. He helps me analyse any problem. When I want to participate in extra-curricular activities, he gives me resources and doesn't mind that sometimes this is not part of the program leading to exams. And even if I get poor results in other examinations, he does not scold me; he helps me.

Pak-hei commented:

The biggest influence on me was my parents. They supported my learning a lot. When I was admitted to Form 1, I found it very hard to adjust to the huge amount of homework. I could not hand in my homework on time. My parents comforted me and told me not to be so stressed. Although they do not have [a high level of education], they were willing to hire a tutor to teach me to do the homework.

Sze-pui mentioned her mother's involvement in guiding her homework:

My mother helps me check the homework. If she finds I have made a mistake in 
Running Head: Personal and environmental factors affecting Hong Kong high-ability students' school satisfaction

my work, she tells me to do the corrections. If I still do it wrong, she gives me hints about the answers.

Overall, these students described their parents as responsive to their needs whenever they faced problems. Despite these parents' high expectations, they supported their children in setting achievable goals and found ways to help them to succeed.

Talent development opportunities

These students commented that their schools provided the right challenges to enhance their interest in learning and to help them become even better at what they already did well. Many students mentioned their participation in school-sponsored extra-curricular activities, stating that these activities helped them maximise their potential. Sze-pui reported:

I like music, and the school encouraged me to join different competitions related to music. My teachers recommended that I learn another musical instrument to expand my music talents.

Yin-mei commented:

Playing basketball is my favourite hobby. My teacher is encouraging me to join the school basketball team, so this will become my goal for next year. I really want to join the team and be a good team player. 
Running Head: Personal and environmental factors affecting Hong Kong high-ability students' school satisfaction

Ho-fai, a Primary 6 boy, reported:

I am good at playing badminton. I want to learn more new techniques to advance my badminton skills. I wish to sign up for the school badminton team because I believe that by practicing more with students at a more advanced level, I could do better. Contributing to the school badminton team is an honour.

Yuk-yee added:

I think by participating in school activities, such as the house activities, we develop a sense of belonging to the school.

Yuk-yee also provided a typical example of how the teachers provided an appropriate enrichment opportunity that reinforced her academic confidence:

I enjoy integrated science and mathematics very much. When I was in primary school, the curriculum was too easy for me. For instance, there was only a course called General Studies. When I studied the topic of electricity in primary school, I didn't really learn much about the subject. Now, the same topic is taught again in secondary school, but the teacher helps us to problem-solve and shows us different themes related to electricity. And now I am also gaining more knowledge of chemistry and find the subject really fun.

Some participants also reported that their schools offered students the chance to work on stimulating, creative products in self-selected areas. Man-hoo described a school task that 
Running Head: Personal and environmental factors affecting Hong Kong high-ability students' school satisfaction

allowed him to show his talent in the final product:

I like my school because there are a lot of activities that are not directly academic.

We come to school not just to study, but also to participate in things such as the school sports team and drama club. Every year, we have an inter-class talent competition. We have to organise it ourselves, and the parents are invited to school to watch the show. I like it because we can use dancing and drama to express the themes. I enjoy doing these with my classmates so much. When we are given this kind of real task, we want to do our best for the school.

It was clear from the comments in the above section that allowing students to pursue their own interests and develop their creativity and talents had a strongly positive effect on their level of school satisfaction. Instead of regarding extra-curricular activities as something that distracted them from schoolwork, the students perceived these activities as permitting them to stretch themselves to show their talent.

\section{Discussion and Conclusions}

This study explored the personal and environmental influences that affect high-ability students' school satisfaction. Some of the influences on satisfaction may be unique to the academic and social environment in Hong Kong and other Chinese societies (e.g., traditional 
Running Head: Personal and environmental factors affecting Hong Kong high-ability students' school satisfaction

beliefs about the role of personal effort, high expectations and pressure from parents to do well, school pressures related to examinations). This evidence supports the view that school satisfaction has a cultural component and is likely to vary to some extent between students in the West and the East.

The personal attribute that may be associated most significantly with school satisfaction for high-ability Chinese adolescents is what can be regarded as 'hope' - which is interpreted here as 'goals and aspirations for the future'. Students whose hopes and aspirations were being met had the highest levels of satisfaction with their schools. It is pertinent here to cite Sydner's (2001) 'theory of hope', which proposes that goals, goal-oriented thoughts and goal-oriented motivation are all bound together and if supported and encouraged will lead to success and satisfaction. In the Hong Kong education system, with its emphasis on public examinations and with family and community expectations that students will do well (Fong \& Yuen, 2011), it was not surprising that students' satisfaction with their schools depended to some degree on the support the schools provided for succeeding academically. However, a surprising finding was that some of the goals students set themselves were not related in any way to academic success but rather to other interests they wished to develop. Schools that offered various opportunities for talent development were greatly valued by the students, and this in turn raised their level of school satisfaction.

It is noteworthy that in most Chinese families, socially desirable values such as filial 
Running Head: Personal and environmental factors affecting Hong Kong high-ability students' school satisfaction

piety and achievement motivation are considered important for attaining accomplishments that can bring honour to the family (Chao, 1994; McBride-Chang \& Chang, 1998). In this study, it was assumed that high parental expectations would undermine students' enjoyment of school, as they might feel pressure if they could not perform well. However, this was not necessarily the case for the Chinese adolescents interviewed. Our findings revealed that these students found themselves motivated to do their best to achieve not only for themselves, but also for their parents. From the students' perspectives, their parents might have had high expectations for them, but they also fully supported their children's learning, whether emotionally, instrumentally or even financially. With parental support, high-ability students could cope with academic pressure and feel satisfied with their own learning. According to the work of $\mathrm{Wu}$ and Chao (2005) on the cultural basis of parenting, the type of personal warmth and support perceived by Chinese adolescents may not be the same as the dominant Western type of warmth and support, which is often characterised as overt and directly expressive. Instead, $\mathrm{Wu}$ and $\mathrm{Chao}$ found that adolescents from Asian American families reported that their kind of parental support was the 'you just know' type. It took the form of instrumental support, such as youth economic support, or even unspoken parental sacrifice (Russell et al., 2010). The differences reported in our study may be indications of ethnically distinct experiences of and meanings associated with warmth and support.

Teacher support in the school environment appeared to influence students' school 
Running Head: Personal and environmental factors affecting Hong Kong high-ability students' school satisfaction

satisfaction - a finding consistent with other research (e.g., Danielsen et al., 2009). These students perceived teachers as supportive when they showed real concern for students' emotional state, used differentiated teaching strategies, acknowledged students' academic success and demonstrated fairness to students. Contrary to the common belief that students feel stressed when facing heavy assignments and examinations (Vaughan, 2014), the narratives here revealed that these Chinese students viewed instances of teachers putting pressure on them to learn as a positive form of support and motivation. They recognised that teachers' strict behaviour kept them on track. Unlike the West, where students might view such teachers negatively as 'authoritarian', the Chinese students regarded them in a positive light. Support for this view is found in research that compared Chinese teachers with Australian teachers (Ho, 2001). Australian teachers tended to consider too much teacher control to be detrimental because it lessened students' motivation and could negatively affect their perception of school, while Chinese teachers and their students regarded such direct control as coming from a culture with a strong concern for love, care and nurturing.

In the collective Chinese culture, where peer conformity is stressed, it was predicted that students with high ability would often be afraid to show their talents in front of their classmates. Because their talents might make them stand out from their peers, they would try to hide their abilities to be accepted by the group. However, this 'forced choice dilemma' was not apparent in the evidence we collected. In our findings, the students showed their 
Running Head: Personal and environmental factors affecting Hong Kong high-ability students' school satisfaction

satisfaction with their school lives that involved a group of classmates who shared similar interests and supported their learning. They revealed their happiness about having the chance to talk to classmates who had common goals and with whom they could exchange tips on how to improve their skills or knowledge. This showed that enabling students to find friends with whom they could talk and engage in shared intellectual or extra-curricular activities could help students build up their sense of belonging at school.

One important finding in this study was that achieving academic excellence was not the sole factor influencing school satisfaction. The students' narratives and self-reporting provided insight into an often-overlooked area: what the school satisfaction of high-ability students looks like and what personal and environmental factors they believe to be influencing their school satisfaction.

This research showed that the cultural and school-related social context influenced high-ability Chinese adolescents' school satisfaction. In the West, there is evidence that external factors, such as opportunities and resources available inside and outside school and the support given by significant people, are powerful influences (Subotnik et al., 2011). In this study, the students reported that their school satisfaction came partly from strong connections with their teachers, supportive classmates and families. Studies have identified these variables as important for facilitating learning and motivation in high-ability students (Fong \& Yuen, 2014; Garrett et al., 2010; Gottfried et al., 1994; Ingram et al., 2007; Reis et 
Running Head: Personal and environmental factors affecting Hong Kong high-ability students' school satisfaction

al., 2005). The present study found that Chinese high-ability students particularly valued the strong parental support given to them for their schoolwork. This finding reinforces the importance of home-school partnerships and effective parent-child communication to help all students set attainable goals and work towards them successfully.

\section{Implications for Practice}

The results of this study provided insights for guidance personnel concerned with the well-being of high-ability students in school. The qualitative data indicated the major influences affecting school satisfaction and suggested potential areas for the further enhancement of the well-being of high-ability students in the school context. Schools that adopt a strength-based approach that encourages positive teacher-student relationships, builds on students' strengths, values each individual and offers new opportunities can serve to increase students' satisfaction with school and also increase students' 'school connectedness' (Blum, 2005; Schapps, 2003).

The high-ability students in this research revealed that goal-directed thoughts and self-discipline were the personal assets that increased their school satisfaction. To enhance high-ability students' capacity in these two domains, guidance personnel can work with the students to make individualised strength-based profiles and help them set personal goals. Parents and teachers can work with the students together to formulate plans to realise their 
Running Head: Personal and environmental factors affecting Hong Kong high-ability students' school satisfaction

dreams. Guidance personnel can strengthen the communication among students, parents and teachers to help the students reach their goals. Guidance personnel and teachers can identify students at risk who seem to have a negative attitude toward school and teachers and attempt to effect change by offering support, building on students' strengths and making them feel acknowledged and valued. Where appropriate, group intervention can also be provided to give them strategies for coping with stress and to establish a close friend support network. Schools can also assign teachers as mentors to help students who are unhappy with school by talking with them about their problems and developing plans to tackle obstacles in school.

Students in the current investigation indicated that environmental factors, such as support from teachers, classmates and parents, had a significant influence on the way they perceived their school lives. We suggest that psychologists and guidance personnel working in and with schools can play a significant role in educating their school communities about school satisfaction research and talent development practices and can serve students, teachers and parents by creating opportunities for listening, dialogue and partnership. When guidance personnel create a safe place for listening to the needs of students, especially the high-ability group, teachers and other school staff can change the school climate by working with the students together. Workshops can be organised for parents to highlight the importance of both high expectations and high support in facilitating their children's learning. The students in this study also provided a glimpse of how the 'forced choice dilemma' was offset when they 
Running Head: Personal and environmental factors affecting Hong Kong high-ability students' school satisfaction

found peers who shared similar interests and valued academic achievement (Moon, 2009).

Given the fierce academic competition in Hong Kong, where students are told to excel in their personal achievement, continued exploration of the role of school satisfaction is warranted, even though certain beliefs may clash with the collective culture of peer acceptance.

In doing this work, guidance personnel can join the international movement towards a more strength-based, responsive and whole-child-centred approach to building students' school satisfaction and talents. In the process, guidance personnel can actively listen to the voices of the students and consider whether any cultural differences should be accounted for as they seek to change the school environment to meet the students' developmental needs.

\section{Limitations and Future Directions}

This study is one of the first to explore school satisfaction in a particular population of high-ability students in Hong Kong, but two limitations should be pointed out. First, the sample size was small $(N=21)$ and taken from only from Primary 4 to Secondary 3 classes.

The findings regarding influences on school satisfaction may not hold for younger or older students. Future studies should aim to interview a much larger sample and a fully representative age range. Such research could focus on understanding more about age-level differences in the acquisition of school satisfaction. Longitudinal monitoring could then be 
Running Head: Personal and environmental factors affecting Hong Kong high-ability students' school satisfaction

used to identify the developmental trajectory of school satisfaction from primary to secondary and even in tertiary education settings.

Second, the selection of participants for this study relied heavily on the judgment of the teachers at each school to identify high-ability students who exhibited strong satisfaction and engagement with school. In future studies, it would be advisable to supplement school nomination with a more objective method for selection purposes (e.g., standardised pre-testing of students). 
Running Head: Personal and environmental factors affecting Hong Kong high-ability students' school satisfaction

\section{References}

Ainley, J., Foreman, J., \& Sheret, M. (1991). High school factors that influence students to remain in school. The Journal of Educational Research, 85(2), 69-80.

Ash, C. \& Huebner, S.E. (1998). Life satisfaction reports of high-ability middle school children. School Psychology Quarterly, 13(4), 310-321.

Baker, J. A. (1998). The social context of school satisfaction among urban, low income, African-American students. School Psychology Quarterly, 13, 25-44.

Baker, J. A. (1999). Teacher-student interaction in urban at-risk classrooms: differential behavior, relational quality, and student satisfaction with school. Elementary School Journal, 100, 57-70.

Baker, J. A., \& Maupin, A. N. (2009). School satisfaction and children's positive school adjustment. In R. Gilman, E. S. Huebner, \& M. J. Furlong (Eds.), Handbook of positive psychology in schools (pp. 189-196). New York: Routledge.

Baker, J. A., Dilly, L., Aupperlee, J., \& Patil, S. (2003). The developmental context of school satisfaction: Schools as psychologically healthy environments. School Psychology Quarterly, 18, 206-222.

Baumrind, D. D. (1978). Parental disciplinary patterns and social competence in children. Youth \& Society, 9, 239-251.

Beckman, L., Hagquist, C., and Hellström, L. (2012). Does the association with 
Running Head: Personal and environmental factors affecting Hong Kong high-ability students' school satisfaction

psychosomatic health problems differ between cyber bullying and traditional bullying? Emotional and Behavioral Difficulties, 17, 421-434

Biggs, J. B. (1996). Western misperceptions of the Confucian-heritage learning culture. In J. B. Biggs \& D. Watkins (Eds.), The Chinese learner: Cultural, psychological and contextual influences (pp. 45-67). Hong Kong: Comparative Education Research Centre.

Blum, R.W. (2005). A case for school connectedness. The Adolescent Learner, 62(7), 16-20.

Braun, V., \& Clarke, V. (2006). Using thematic analysis in psychology. Qualitative Research in Psychology, 3, 77-101.

Chan, D. W. (2003). Adjustment problems and multiple intelligences among high-ability students in Hong Kong: The development of the revised Student Adjustment Problems Inventory. High-ability Studies, 14(1), 41-54.

Chan, D. W. (2008). Goal orientations and achievement among Chinese high-ability students in Hong Kong. High-ability Studies, 19(1), 37-51.

Chan, D. W. (2012). Life satisfaction among highly achieving students in Hong Kong: do gratitude and the 'good enough mindset' add to the contribution of perfectionism in prediction? Educational Psychology, 32(5), 613-626.

Chao, R. (1994). Beyond parental control and authoritarian parenting style: Understanding Chinese parenting through the cultural notion of training. Child Development, 65, 
Running Head: Personal and environmental factors affecting Hong Kong high-ability students' school satisfaction

1111-1120.

Chao, R. (1996). Chinese and European-American mothers' beliefs about the role of parenting in children school success. Journal of Cross-Cultural Psychology, 27, 403-423.

Chao, R., \& Sue, S. (1996). Chinese parental influences and their children's school success: A paradox in the literature on parenting styles. In S. Lau (Ed.), Growing up the Chinese way: Chinese child and adolescent development (pp. 93-120). Hong Kong: Chinese University Press.

Cheung, P.C., \& Lau, S. (1985). Self-esteem: Its relationship to the family and school social environments among Chinese adolescents. Youth and Society, 16, 438-456.

Chirkov, V. I., \& Ryan, R. M. (2001). Parent and teacher autonomy-support in Russian and U.S adolescents: Common effects on well-being and academic motivation. Journal of Cross-Cultural Psychology, 32, 618-635.

Cock, D., \& Halvari, H. (1999). Relations among achievement motives, autonomy, performance in mathematics, and satisfaction of pupils in elementary school. Psychological Reports, 84, 983-997.

Danielsen, A. G., Samdal, O., Hetland, J., \& Wold, B. (2009). School-related social support and students' perceived life satisfaction. The Journal of Educational Research, 102(4), 303-320. 
Running Head: Personal and environmental factors affecting Hong Kong high-ability students' school satisfaction

Deci, E. L., \& Ryan, R. M. (1987). The support of autonomy and the control of behavior. Journal of Personality and Social Psychology, 53, 1024-1037.

DeSantis-King, A. L., Huebner, S., Suldo, S. M., \& Valois, R. F. (2006). An ecological view of school satisfaction in adolescence: Linkages between social support and behavior problems. Applied Research in Quality of Life, 1, 279-295.

DiBartolo, P. M. \& Rendón, M. J. (2012). A critical examination of the construct of perfectionism and its relationship to mental health in Asian and African Americans using a cross-cultural framework. Clinical Psychological Review, 32, 139-152.

Diener, E. (2000). Subjective well-being: The science of happiness, and a proposal for a national index. American Psychologist, 55, 34-43.

Eriksson, C., Eriksson, L., Fischbein, S., et al. (2010). School, learning and mental health: A systematic review. Stockholm: The Royal Swedish Academy of Sciences, The Health Committee.

Farrall, J., \& Henderson, L. (2015). Supporting your high-ability and talented child's achievement and wellbeing: A resource for parents. Adelaide, SA: Association for Independent Schools.

Ferguson, Y. L., Kasser, T., \& Jahng, S. (2010). Differences in life satisfaction and school satisfaction among adolescents from three nations: The role of perceived autonomy support. Journal of Research on Adolescence, 21, 649-661. 
Running Head: Personal and environmental factors affecting Hong Kong high-ability students' school satisfaction

Fong, R. W., \& Yuen, M. T. (2011). Perfectionism in Chinese elementary school students: Validation of the Chinese adaptive/maladaptive perfectionism scale. Journal of Talent Development and Excellence, 3(2), 203-213.

Fong, R. W., \& Yuen, M. (2014). Perfectionism and Chinese high-ability learners. Roeper Review, 36(2), 81-91.

Fouladchang, M., Kohgard, A., \& Salah, V. (2010). A study of psychological health among students of gifted and nongifted high schools. Procedia Social and Behavioral Sciences, 5, 1220-1225.

Freeman, J. (1996). The early development and education of highly able young children. In Cropley, A. J. and Dehn, D. (Eds.), Fostering the growth of high-ability: European perspectives, 165-171. Norwood, NJ: Ablex Publishing Corporation.

Garrett, T., Antrop-Gonzales, R., \& Velez, W. (2010). Examining the success factors of high-achieving Puerto Rican male high school students. Roeper Review, 32, 106-115.

Gilman, R., \& Huebner, E. S. (2006). Characteristics of adolescents who report very high life satisfaction. Journal of Youth and Adolescence, 35, 293-301.

Ginsberg, E. (1992). Not just a matter of English. HERDSA, 14, 6-8.

Gottfried, A. W., Gottfried, A. E., Bathurst, K., \& Guerin, D. (1994). High-ability IQ: Early developmental aspects - The Fullerton Longitudinal Study. New York: Plenum.

Gross, M. U. M. (1994). Responding to the social and emotional needs of high-ability 
Running Head: Personal and environmental factors affecting Hong Kong high-ability students' school satisfaction

children. Australian Journal of Education, 3(2), 4-10.

Gross, M. U. M. (1989). The pursuit of excellence or the search for intimacy? The forced

choice dilemma of gifted youth. Roeper Review, 11, 189-194.

Gross, M. U. M. (1998). The 'me' behind the mask: Intellectually gifted students and the search for identity. Roeper Review, 20, 167-174.

Gustafsson, J. E., Allodi Westling, M., Alin Åkerman, B., Eriksson, C., Eriksson, L., Fischbein, S., Granlund, M., Gustafsson, P., Ljungdahl, S., Ogden, T., \& Persson, R. S. (2010). School, learning and mental health: A systematic review. Stockholm: The Royal Swedish Academy of Sciences.

Ho, I. T. (2001). Are Chinese teachers authoritarian? In D.A. Watkins \& J.B. Biggs (Eds.), Teaching the Chinese learner: Psychological and pedagogical perspectives (pp. 99-114). Hong Kong: CERC.

Hsieh, H., \& Shannon, S. (2005). Three approaches to qualitative content analysis. Qualitative Health Research, 15(9), 1277-1287.

Huebner, E. S. (1994). Preliminary development and validation of a multidimensional life satisfaction scale for children. Psychological Assessment, 6, 149-158.

Huebner, S. E., Ash, C., \& Laughlin, J. E. (2001). Life experiences, locus of control, and school satisfaction in adolescence. Social Indicators Research, 55(2), 167-183.

Huebner, S. E., \& Diener, C. (2008). Research on life satisfaction of children and youth: 
Running Head: Personal and environmental factors affecting Hong Kong high-ability students' school satisfaction

Implications for the delivery of school-related services. In M. Eid \& R. Laresen (Eds.), The science of subjective well-being (pp. 376-392). New York: Guilford Press.

Huebner, E. S., Gilman, R., Reschly, A., \& Hall, R. (2009). Positive schools. In S. J. Lopez \& C. R. Snyder (Eds.), Oxford handbook of positive psychology (2nd ed., pp. 561 - 569). Oxford: Oxford University Press.

Hui, E. (2000). Guidance as a whole school approach in Hong Kong: From remediation to student development. International Journal for The Advancement of Counselling, 22(1), 69-82.

Hui, E., \& Sun, R. (2010). Chinese children's perceived school satisfaction: The role of contextual and intrapersonal factors. Educational Psychology, 30, 155-172.

Ingram, M., Wolfe, R. B., \& Lieberman, J. M. (2007). The role of parents in high-achieving schools serving low-income, at-risk populations. Education on Urban Society, 39, $479-497$.

Jung J. Y., McCormick, J., \& Gross, M. (2012). The Forced choice dilemma: A model incorporating idiocentric/allocentric cultural orientation. Gifted Child Quarterly, $56(1), 15-24$.

Karatzias, A., Power, K. G., Flemming, J., Lennan, F., \& Swanson, V. (2002). The role of demographics, personality variables and school stress on predicting school satisfaction/dissatisfaction: Review of the literature and research findings. 
Running Head: Personal and environmental factors affecting Hong Kong high-ability students' school satisfaction

Educational Psychology: An International Journal of Experimental Educational

Psychology, 22(1), 33-50.

Kasdan, T. B., \& Yuen, M. (2007). Whether highly curious students thrive academically depends on perceptions about the learning environment: A study of Hong Kong adolescents. Motivation and Emotion, 31(4), 260-270.

Leiber, E., Fung, H., \& Leung, P. W. L. (2006). Chinese child-rearing beliefs: Key dimensions and contributions to the development of culture-appropriate assessment. Asian Journal of Social Psychology, 9(2), 140-147.

Lewis, A. J., Huebner, E. S., Reschly, A. L., \& Valois, R. F. (2009). The incremental validity of positive emotions in predicting school functioning. Journal of Psychoeducational Assessment, 27, 397-408.

Leung, F. K. S. (2012). Hong Kong SAR. In I.S. Mullis, M. O. Martin, C.A. Minnich, G. M. Stanco, A. Arora \& V.A.S. Centurino (Eds.), TIMSS 2011 encyclopedia: Education policy and curriculum in mathematics and science, Vol 1: A-K (pp. 367-380). TIMSS \& PIRLS International Study Center. Boston: Lynch School of Education, Boston College.

Li, J. (2001). High abilities and excellence: A cultural perspective. In L. V. Shavinina \& M. Ferrari (Eds.), Beyond knowledge: Extracognitive aspects of developing high-ability. The Educational Psychology Series (pp. 187-208). Mahwah, NJ: Erlbaum. 
Running Head: Personal and environmental factors affecting Hong Kong high-ability students' school satisfaction

Malecki, C. K., \& Demaray, M. K. (2002). Measuring perceived social support: Development of the child and adolescent social support scale (CASSS). Psychology in the Schools, $39,1-18$.

Miles, M. B., \& Huberman, A. M. (1994). Qualitative data analysis: An expanded sourcebook (2nd ed.). Thousand Oaks, CA: Sage.

Moon, S. M. (2009). Myth 15: High-ability students don't face problems and challenges. Gifted Child Quarterly, 53(4), 274-276.

Neihart, M. (1999). The impact of giftedness on psychological well-being: What does the empirical literature say? Roeper Review, 22, 10-17.

Okun, M., Braver, M. W., \& Weir, R. M. (1990). Grade level differences in school satisfaction. School Indicators Research, 22(4), 419-427.

Park, N., \& Huebner, E. S. (2005). A cross-cultural study of the levels and correlates of life satisfaction among adolescents. Journal of Cross-Cultural Psychology, 36, 444-456.

Park, N., Peterson, C., \& Seligman, M. E. P. (2004). Strengths of character and well-being. Journal of Social and Clinical Psychology, 23, 603-619.

Peterson, J. S. (2009). Myth 17: Gifted and talented individuals do not have unique social and emotional needs. Gifted Child Quarterly, 53(4), 280-282.

Pomerantz P., \& Pomerantz, K. (2002). Listening to able underachievers: Creating opportunities for change. London: Fulton. 
Running Head: Personal and environmental factors affecting Hong Kong high-ability students' school satisfaction

Purkey, W., \& Novak, J. (1996). Inviting school success: A self-concept approach to teaching (3rd ed.). Belmont, CA: Wadsworth.

Reeve, J., \& Jang, H. (2006). What teachers say and do to support students' autonomy during a learning activity. Journal of Educational Psychology, 98, 209-218.

Reis, S. A., Colbert, R. D., \& Hébert, T. P. (2005). Understanding resilience in diverse, talented students in an urban high school. Roeper Review, 27, 110-120.

Reyes, M. R., Brackett, M. A., Rivers, S. E., White, M., \& Salovey, P. (2012). Classroom emotional climate, student engagement, and academic achievement. Journal of Educational Psychology, 104, 700-712.

Reynolds, C. R., \& Bradley, M. (1983). Emotional stability of intellectually superior children versus nongifted peers as estimated by chronic anxiety levels. School Psychology Review, 1, 190-194.

Roome, J. R., \& Romney, D. M. (1985). Reducing anxiety in gifted children by inducing relaxation. Roeper Review, 7, 177-179.

Russell, S. T., Crockett, L. J., \& Chao, R. K. (2010). Conclusions: The role of Asian American culture in parenting and parent-adolescent relationships. In S. Russell, L. Crockett, \& R. Chao (Eds.), Asian American parenting and parent-adolescent relationships. Advancing responsible adolescent development (pp. 117-128). New York:

Springer. 
Running Head: Personal and environmental factors affecting Hong Kong high-ability students' school satisfaction

Ryan, A. M. (2001). The peer group as a context for the development of young adolescent motivation and achievement. Child Development, 72, 1135-1150.

Schapps, E. (2003). The role of supportive school environments in promoting academic success. Sacramento, CA: California Department of Education Press.

Scholwinski, E., \& Reynolds, C. R. (1985). Dimensions of anxiety among high IQ children. Gifted Child Quarterly, 29, 125-130.

Snyder, C. R. (2000). Handbook of hope: Theory, measures, and application. San Diego, CA: Academic Press.

Snyder, C. R., Sympson, S. C., Michael, S. T., \& Cheaven, J. (2001). Optimism and hope constructs: Variants on a positive expectancy theme. In E. C. Chang (Ed.), Optimism and pessimism: Implications for theory, research and practice (pp. 101-125). Washington, DC: American Psychological Association.

Snyder, C. R. (2000). Handbook of hope. San Diego, CA: Academic Press.

Subotnik, R. F., Olszewski-Kubilius, P., \& Worrell, F. C. (2011). Rethinking giftedness and gifted education: A proposed direction forward based on psychological science. Psychological Science in the Public Interest, 12, 3-54.

Sue, S. \& Okazaki, S. (1990). Asian-American educational achievements: A phenomenon in search of an explanation. American Psychologist, 45(8), 913-920.

Suldo, S. M., Friedrich, A. A., White, R., Farmer, J., Minch, D., \& Michalowski, J. (2009). 
Running Head: Personal and environmental factors affecting Hong Kong high-ability students' school satisfaction

Teacher support and adolescents' subjective well-being: A mixed-methods investigation. School Psychology Review, 38, 67-85.

Suldo, S. M., Shaffer, E. S., \& Riley, K. (2008). A social-cognitive-behavioral model of academic predictors of adolescents' life satisfaction. School Psychology Quarterly, 23, $56-69$.

Tse, S. K. (2012). Hong Kong SAR. In I. V. S. Mullis, M. O. Martin, C. A. Minnich, K. T. Drucker \& M. A. Regan (Eds.). PIRLS 2011 encyclopedia: Education policy and curriculum in reading (pp. 287-299). TIMSS \& PIRLS International Study Center. Boston: Lynch School of Education, Boston College.

Valois, R. F., Zullig, K. J., Huebner, E. S., \& Drane, J. W. (2009). Youth developmental assets and perceived life satisfaction. Is there a relationship? Applied Research on Quality of Life, 4, 315-331.

Vaughan, R. (2014). When school stress becomes a matter of life and death. (Teenage suicide rate in China). Times Educational Supplement, May 23, 2014, Issue 5096, pp. 12-14.

Vera, E. M., Moallem, B. I., Vacek, K. R., Blackmon, S., Coyle, L. D., Gomez, K. L., \& Steele, J. C. (2012). Gender differences in contextual predictors of urban, early adolescents' subjective well-being. Journal of Multicultural Counseling and Development, 40(3), 174-183.

Verkuyten, M., \& Thijs, J. (2002). School satisfaction of elementary school children: The role 
Running Head: Personal and environmental factors affecting Hong Kong high-ability students' school satisfaction

of performance, peer relations, ethnicity and gender. Social Indicators Research, 59, 203-228.

Watson, B. (2007). The analects of Confucius. New York: Columbia University Press.

Wu, C. X., \& Chao, R. K. (2005). Intergenerational cultural conflicts for Chinese American youth with immigrant parents: Norms of parental warmth and the consequences. International Journal of Behavioral Development, 29, 516-523.

Yuen, M. T., \& Fong, R. W. (2013). Social-emotional development of Chinese high-ability students: A review based within the actiotope model of giftedness. In S. N. Phillipson, H. Stoeger \& A. Ziegler (Eds.), Exceptionality in East Asia: Explorations in the actiotope model of giftedness (pp. 132-146). London, UK: Routledge. 
Running Head: Personal and environmental factors affecting Hong Kong high-ability students' school satisfaction

Table 1 Demographic information of informants $(N=21)$

\begin{tabular}{lllll}
\hline Grouping & Gender & Grade & Age & School \\
\hline Primary & F & P.4 & 9 & 1 \\
& M & P.5 & 10 & 1 \\
& M & P.6 & 11 & 1 \\
& F & P.4 & 9 & 2 \\
M & P.4 & 9 & 2 \\
F & P.5 & 10 & 2 \\
M & P.5 & 10 & 2 \\
F & P.4 & 9 & 3 \\
M & P.4 & 9 & 3 \\
F & P.5 & 11 & 3 \\
F & P.6 & 12 & 3 \\
F & F.1 & 13 & 4 \\
F & F.2 & 13 & 4 \\
M & F.3 & 14 & 4 \\
M & F.1 & 11 & 5 \\
M & F.1 & 11 & 5 \\
M & F.1 & 11 & 5 \\
M & F.1 & 11 & 6 \\
F & F.2 & 12 & 6 \\
F & F.2 & 12 & 6 \\
F & F.3 & 13 & \\
\hline
\end{tabular}


Running Head: Personal and environmental factors affecting Hong Kong high-ability students' school satisfaction

\section{Appendix A}

Interview Guide

School

(1) Do you like this school?

(2) Do you feel a sense of belonging in this school?

(3) What are the things you like about your present school life?

(4) What are the things you dislike about your school life?

(5) Do you have any main goals for the future?

(6) How does the school help you to accomplish your goals?

Teacher-student relationship

(1) Tell me about teacher-student relationships at your school. How do teachers and students relate to one another?

(2) Can you describe your own relationship with your teachers?

(3) Do you have any teachers whom you can count on?

(4) Do you think teachers are willing to help when you have problems? Why?

(5) Do you seek help from your teachers when you have problems? In which aspects? Why?

(6) How do you want your teacher to support you in the future?

Family

(1) Tell me about your relationships with your family members.

(2) Do you think your family members take an active interest in your school life?

(3) Do you think your family members are willing to help when you have problems?

(4) Do you turn to your family members to seek help when you have problems?

a. Who helps you most?

b. In which areas of your schoolwork and life do they help?

c. What forms of help do they provide?

(5) How do you want your family to support you in the future?

\section{Classmates}

(1) Tell me about your relationship with your classmates.

(2) Do you have any classmates whom you can count on?

(3) Do you think your classmates are willing to help when you have problems? 
Running Head: Personal and environmental factors affecting Hong Kong high-ability students' school satisfaction

(4) Do you turn to your classmates to seek help when you have problems?

a. Who is willing to help you?

b. Which aspects of your schoolwork or life are helped by classmates?

c. How exactly do they provide help?

(5) How do you want your classmates to support you in the future? 